\title{
A Study on the "Lantern Song" of Han People in Gong County of Southern Sichuan
}

\author{
Li Jiang \\ Aba Teachers University \\ Aba, China 623002
}

\begin{abstract}
Gong County in Yibin, Sichuan Province is a gathering place of minorities. As a local intangible cultural heritage, "lantern song" was born with the historical development of Gong County and has a profound cultural heritage. Its music absorbs local cultural materials, making it has the artistic features with rich local culture. The songs are rich in content and deep in meaning with diverse singing style and the unique vocal music. The music shows the diversified development trend. The local "lantern song" is used as an important form of expressing emotions when the local festival is celebrated, of which the performance is very regional. This article goes deep into the Gong county of Yibin to conduct a data survey on the local "lantern song", organizes and summarizes the data, records and analyzes the collected songs, and presents the local songs in the form of music scores. It is of far-reaching significance to respond to the local call of "inheriting and popularizing national folk culture to enhance the influence of local culture".
\end{abstract}

Keywords-Gong county; lantern song; sing; artistic characteristics

\section{INTRODUCTION}

Yibin in southern Sichuan is vast in territory with favorable geography environment and rich resources. According to the "record of Gong County" (the old record) in Guangxu years of Qing dynasty, Gong County was originally the territory of southern Sichuan. After Qin annihilated Kaiming Family, Bo people lived here, so it is called Bo country. It has been over 600 years since it was degraded from state to county in the fourth year of Hongwu of Ming dynasty (1371). The Qin and the early Han dynasties, it was southwestern $\mathrm{Yi}$, which was a place where Han, Miao, Yi and $\mathrm{Yi}$ lived together. Many ethnic groups were settled here and the culture blended, forming a trend of diversified development of local music culture. "Lantern song" of Gong County was born in such a unique environment, with a certain cultural regionality. The "lantern song" at the "playing lantern" ceremony in Gong County refers to singing the song with storyline and characters in the process of "playing lantern", including "car lantern song" and "cattle lantern song". These "lantern songs" have experienced the process of transforming from complication to simplification in the form of singing with the development of the times. The local people divided the "lantern song" according to the content into "history story car lantern song", "modern car lantern song", "folk car lantern song", in order to better spread and sing the various "lantern song". In contrast, the local "cattle lantern song" is relatively simple in terms of singing, melody, tonality, etc. The melody blends that of local minor tune songs, with catchier tune, free rhythm, rich expression form and the singing content is mostly related to the farmer's life. These "lantern songs" form a relatively fixed singing pattern and singing style in the cultural inheritance and development.

This article goes deep into the "Gong" place, researches local song texts and singing vocals, biting words, performances, accompaniment, etc., explores the rules of local song singing, and sorts out local folk songs that appear in the spectrum, which has a certain effect in promoting national folk culture and inheritance of local music.

\section{ANALYSIS OF THE SingING OF "CAR LANTERN SONG"}

The "car lantern song" can be divided into "sevencharacter sentence", "short and long sentences", "antiphonal singing" and "praying song" based on the characters of lyrics and singing forms. According to the singing vocal, it can be divided into: "flat tone with seven-character sentence", "high tone with seven-character sentence", "flat tone sentence", "high tone long sentence" and so on. The local representative repertoire includes: high-tone seven-character sentence "Liu Yin Ji" (1), flat-tone seven-character "Liu Yin Ji" (2), long and short sentences "Duo Yu Niang", and the antiphonal song "Guessing Word", etc. These songs are local typical lantern songs. The tunes of the songs are mellow, melodious, and rich in melody. The modes are mainly composed of five vocal angles, zheng and yu. The rhythm of the songs is cheerful and expressive. Several representative repertoires are selected for singing analysis, as shown in the following figures. 


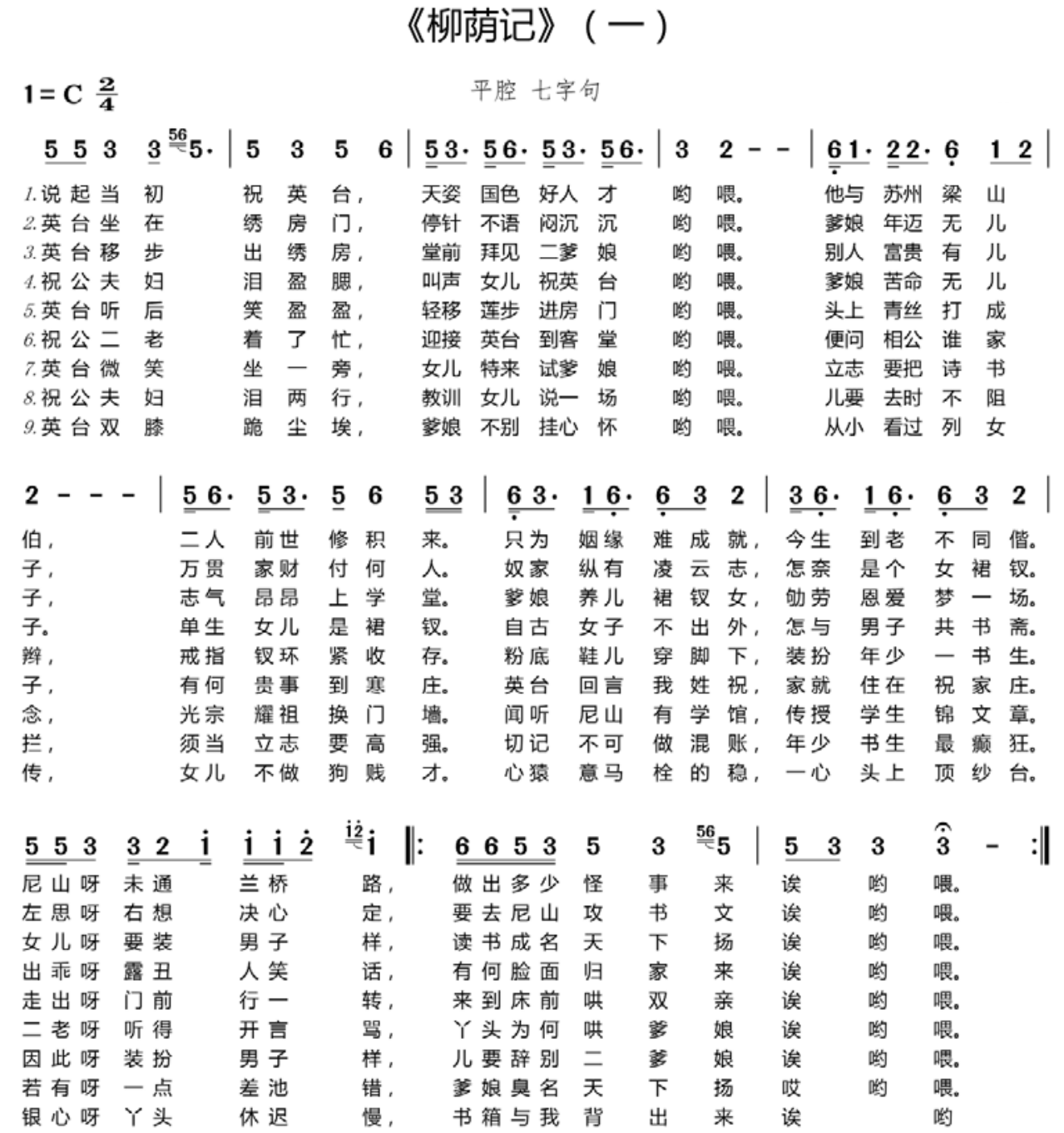

Fig. 1. "Liu Yin Ji" (a) music score.

Dialect notes: originally: 当(dān)初, national beauty: 国 (guí)色, Liang Shanbo: 梁山(sān)伯(béi), Lanqiao Road: 兰桥 路 (lú), how much: 多少(sáo), go to school: 上学(xú)堂, cry out: 泪盈腮(sé)study: 书斋 (zāi), dew: 露(lòu) 有何(hó), ring: 戒(ji) 指(zí)living room: 客(kò)堂, scoundrel: 混账 (záng)

"Liu Yin Ji" in "Fig. 1" is a typical flat-tone sevencharacter car lantern song. The story is about the study of Zhu Yingtai in the academy. The mode of song is E-jue mode and the beat is $4 / 4,6+6$, with the two-sentence symmetry structure, the main tones are five national modes: 1 (gong), 2 (shang), 3 (jue), 5 (zhi), and 6 (yu). The melody rotation method mainly adopt the changing process of second, third, and fourth degrees, and only one degree jumps in seven degrees. The rhythm pattern is mainly based on the eight-point post-attachment point, the twenty-eight rhythm, and the first sixteens and eight after eight rhythms. The first melody of the song is in a zigzag pattern, and the rhythm is changed from sparse to dense. The quarter note rhythm has ups and downs of rhythm, which is a foreshadowing of the emotional direction of the song. The first phrase paused for 4 beat in the shang sound (D), hinting the sentence is transferred to the second sentence. After entering the second phrase, the melody continues to appear four degree big jumps. The music of the song is emotionally excited and the rhythm also changed from dense to sparse. In sharp contrast with the first phrase, the overall rhythm of the song shows a contrast change of relaxation-compact-relaxation, ending 
with the zhi sound (E), and the emotions of Zhu Yingtai's aspirations and her parents' reluctance are showed in detail through music.

The local lyrics based on narrative historical stories and folklore is mostly selected from Beijing opera, aria of Sichuan opera or folklore. The melody of this song is going up and down. In order to increase the color and effect of song singing, the singer often improvises to add a lot of decorative sounds to express the emotions at the end of the song. In order to increase the appeal of the song, the locals often adds the words of the modality, yo, wei, and so on to the end shot of the song. They are used to enrich the emotions of songs or as a fill when the number of words is insufficient to adjust the alignment between the lyrics and the melody and the rhythm between the melody and the lyrics. This feature is also a feature of local folk songs. "Liu Yin Ji" uses "flat tone" in the singing vocal and this vocal performance is characterized by narrower vocal range, less melody change, more regular rhythm, and smoother and beautiful tracks on the melody of the singing. The voice focuses on the lyricism of the song and sings the song in a soft, rounded voice.

The local "lantern song" are composed of vocal singing and instrumental accompaniment. Accompaniment instruments include: gong, yunluo, China cymbals, drums, etc., which are used to remind the song speed, render the singing atmosphere, and prompt the venue, as shown in "Fig. 2":

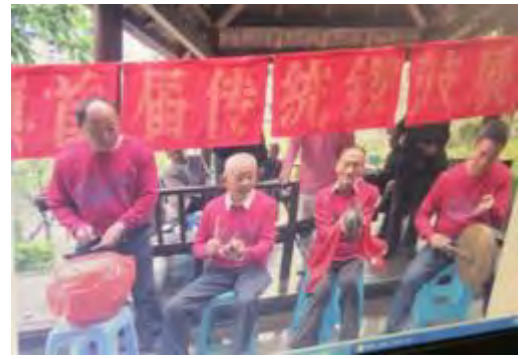

Fig. 2. Local accompaniment instrument.

The lyric of "Liu Yin Ji" (1) is long, with a total of 9 paragraphs. The form of sub-section songs multiple sections of lyrics of this melody are common. The narrative adopts the general-part narrative method. In the first paragraph, the ending of the marriage of Liangshanbo and Zhu Yingtai is generally narrated by using sorrow to set off joy. This paragraph is a sigh of unsatisfactory performance of Liang Shanbo and Zhu Yingtai. During the singing, the singer's tone is slightly sad, the singing rhythm is relatively free, and the singing speed is slightly slower. In the singing of lining words, the vocal accompany of lantern lighter should be consistent with the singer's singing emotions. At this time, the accompaniment songs are sung in local dialects. In comparison, the local dialect is relatively higher than the Mandarin, and the mainly second tone is used. The speed of speech is faster, the tone is more intense, and it also has the characteristics of mixing (a/an), (e/o), (l/n), and level-lingual and cacuminal. Songs sung in local dialects are closer to the lives of local people, and are more likely to resonate their emotion, with the charm of local folk music. The use of the stories of Liang Shanbo and Zhu Yingtai as singing content reflects the urgency of young men and women yearning for free love in the old society.

\section{B. Analysis of the Singing of Long and Short Sentences "Car Lantern Song"}

\section{《窦玉姐》}

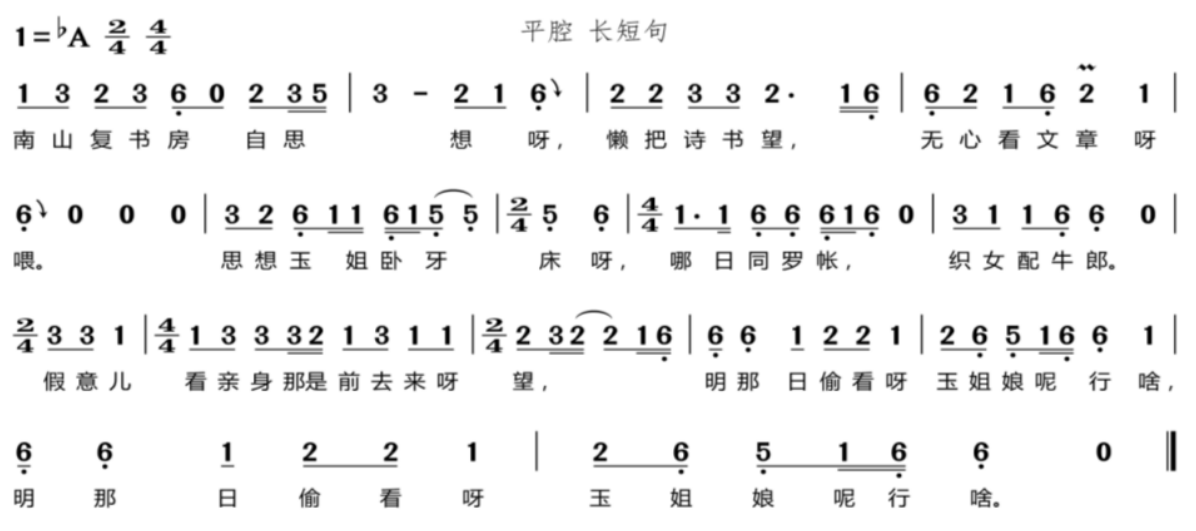

Fig. 3. The music score of Long and short sentence "car lantern song" - "Dou Yujie".

The song "Dou Yujie" is a "folklore" car lantern song in "Fig. 3". The locals compose the words into a car lantern song with a local music style. According to the number of words in the lyrics, the songs are classified into "long and short sentences". As shown in "Fig. 4", the first sentence of the song "南山复书房自思想"(thinking alone in the study in Nanshan) is an eight-character (long) sentence, and then "濑 
把诗书望, 无心看文章" (not feel like to read poems or articles) are five-character (short) sentences, "思想玉姐卧牙床" (guess that yujie may lie on the bed) is a seven-character (short) sentence, "哪日同罗帐, 织女配牛郎" (when can we meet again? just like the milk way lovers) returns to the five characters, and finally returns to the eight-character sentence. This kind of lyrics with short sentence in the middle and long on both sides is called "long and short sentences". This type of lantern song is very representative. The following analysis of melody beats, tonality, song singing, etc. will help to study local culture.

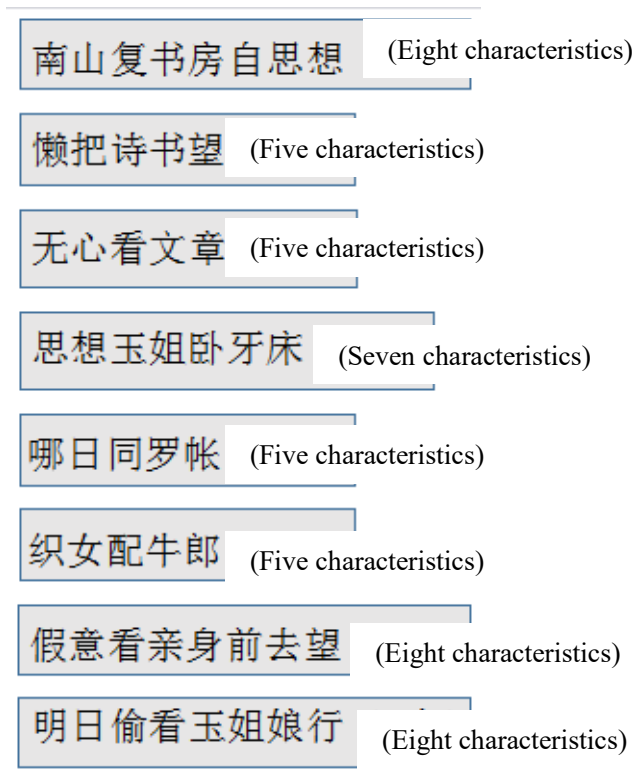

Fig. 4. Composition of long and short sentence "light music" lyrics.

This "Dou Yu Jie" is an F-yu type, composed of 4/4 and $2 / 4$ beats. The 1-5 sections of first sentence of the song fall on the yu sound (F), which stabilizes the tonality; in the second sentence, the sixth to the ninth, a total of 4 sections, use the same reflection deformation of the material (1 65 ) as the first sentence material ( $\left.\begin{array}{lll}2 & 1 & 6\end{array}\right)$, which falls on the yu sound $(\mathrm{F})$; the third sentence (10 bars - 16 bars) starts with the material variation of the first sentence and adds the flower, and finally repeats to enhance the ending feeling. The song ends on $\mathrm{F}$ yu tone.

The song "Duo Yujie" is about the scholar "Sheng Gongzi" who is thinking about Dou Yujie all day long, so that he was uninterested in reading books, and hopes to be able to marry Dou Yujie as soon as possible. The tonality and melody of the song is stronger and the tune repeatedly falls in the main tone, making the singing smoother. The rhythm of the song changes more regularly and it uses mixed beats to express the mood changes of the song. In the fifth section, the song was sung in a down sound to match the melancholy behavior of "having no mood to read articles", which makes the music more natural. Usually during the singing, "doushou" acts as "Dou Yujie", and "Che yaogu" act as Shen Gongzi who reads book idly when showing the urgency of "thinking yujie lying on the bed" all day long. He should pay attention to grasping the tone of singing songs, and not only sing the helpless feeling of "having no mood to read articles", but also show the enthusiasm of "Shang Gongzi" in pursuing "Douyujie" Therefore, the singing of (15) and (6-11) sections should form a sharp contrast in emotion. The speed of songs should change from slow to quick and to slower to express the obvious change in emotion of "Shen Gongzi" to "Dou Yujie" from subtle to warm. At this time, "doushou" should make fun by the side, so that the eager emotion of "Che Yugu" Shen Gongzi "thinking yujie lying on the bed" is more intuitive. It is reflected that at this time, Shen Gongzi's feelings for Dou Yujie have become more and more intense. In the "hope to be together as early as possible, the weaver girl with the cowherd, and intend to visit by himself", the speed express "Sheng Gongzi"s pursuit of "Duo Yujie". The singing speed is slightly faster, until the end of the song "peeking yujie's mother action tomorrow", in order to seek the opportunity of meeting "Dou Yujie" alone, "Shen Gongzi" had to wait yujie's mother to go out before he meets with the beautiful woman. The whole song is played under the funny performance of "Che Yao Gu" and "Doushou", who makes the song very visual and the singing is very interesting.

\section{Analysis of the Singing of the Antiphonal "Car Lantern Song"}

The song consists of four phrases as shown in "Fig. 5", with $3+2+2$ sentence and two sentence structure, $4 / 4$ beat $\mathrm{F}$ jue four tone. The song was sung when the host holds "guessing puzzle" game during picking up the lantern. The singing is in the form of male and female duet. This "Guessing Word" is developed with x x x-motivated rhythm materials. It uses a lot of three or four-degree hopping melody, which justly explains the humorous characteristics of singing. In the rhythm change, the song uses the first eight post-sixteen rhythms, the twenty-eight rhythm, the first eight and the last four points, with rich and varied rhythm to make the music more interesting and humorous. The first two phrases interconnect and develop freely, making the phrases seek commonness among differences and develop tightly. The fourth sentence is the female antiphonal singing, where the rhythm (x x x x ...) of the first paragraph of the first male voice is repeated to highlight the theme of the music. On the whole, the melody of the song revolves around the core three-tones of di, rh, and do combined with the diversified rhythm changes. The melody has a strong ethnic minor style, which is very rich in the regional characteristics of Gong County. 


\section{猜字}

$$
1={ }^{\#} \frac{4}{4}
$$

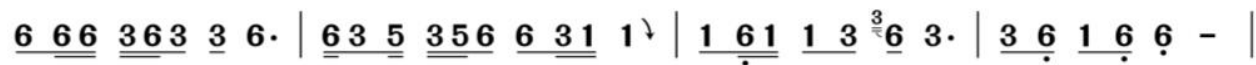

$$
\begin{aligned}
& \text { 1. (男) 一飘嘛在头上, 十字在中央吆喂。八字两边放噻, 日子脚下藏。 } \\
& \text { 2. (男) 一点嘛一横长, 一飘到南洋哅喂。两颗林阴木噻, 生在石头上。 } \\
& \text { 3. (男) 一点嘛一横长, 一飘到南洋哅喂。上十对下十噻, 太阳对月亮。 }
\end{aligned}
$$

\begin{tabular}{|c|c|c|c|c|c|c|c|c|c|c|c|c|c|c|c|c|}
\hline 13 & $\begin{array}{ll}3 & 1 \\
\end{array}$ & $1 \stackrel{3}{=} 6$ & 3 & 1 & 33 & 31 & 1 & - & 366 & $\begin{array}{ll}6 & 3 \\
\end{array}$ & 36 & 3. & 1 & & 3 & 1 \\
\hline ゆ & 想 不 & 不 起 & 㮫 & 情 & 哥 & 帮 & 㠸 & （男 & 寻儿 & 帮 你 & 尔 想 & 噻， & 情 & 哥 & 帮 & \\
\hline 妹 & 想 不 & 不 起 & 噻 & 情 & 哥你 & 帮 个 & 忙。 & 情 & 青 哥儿 & 帮 你 & 尔 想 & 噻， & 情 & 哥 & 帮 & 你 忙 \\
\hline 情 哥 & 帮 你 & 尔 想 & 哦 & 情 & 哥你 & 帮 个 & 忙。 & (男) 情 & 青 哥儿 & 帮 你 & 尔 想 & 噻， & 情 & 哥 & 帮 & 你 忙 \\
\hline
\end{tabular}

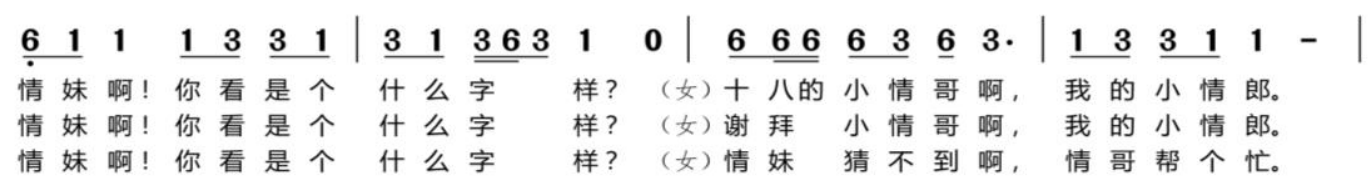

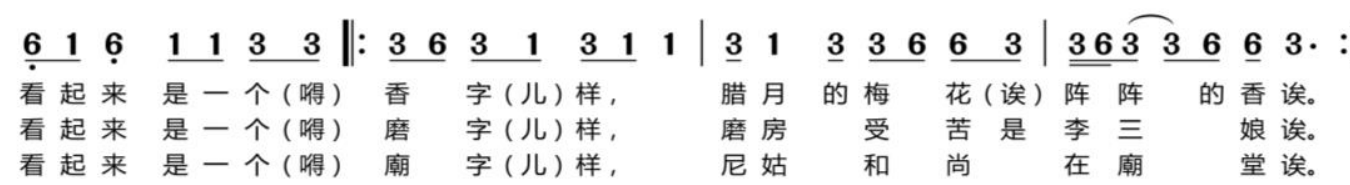

Fig. 5. Music score of Guess the Word.

Dialect notes: eight characters: 八(bá)字, character ten: + (sí)字, the twelfth lunar month 腊(lá)月(yué), my: 我(ó)的, brother: 小情哥(guō), sister: 情(qín)妹(měr), what: 什(sén)么, moon: 月(yué)亮, hidden under the foot: 脚(juó)下藏, on the stone: 石(sí)头上 is:是(sí)个, mill: 磨(mó)房, southeast Asia: 南 (lán)洋, nun:尼(lí)姑, monk: 和(hó)尚(sáng)

The melody of this song blends with the material of the local folk songs. The tunes are closely connected, the melodies are melodious and mellow, and the songs are sung in a cheerful, bright and dexterous voice. The songs use the glide and the chamber to express the subtle emotional changes in the songs. The local slide tone is mostly used in the lyrics at the end of the sentence. For example, in the second section of the song, when actor sings the sentence "the cross is in the center", after biting and singing the word "hello", the sighs go from top to bottom and slides down with the pitch to show the easy and free state of the singer. There are two main characteristics of the local lantern words:

The number of "cattle lantern songs" in Gong County is small, and the content involved is simple. This first song "song for pasturing cattle" in "Fig. 6" imitate "cowherd" who takes cattle to graze on the slope and drink water by the river. The songs are simple and straightforward, with short and smooth tunes. The tune type is $\mathrm{G}$ zhi mode, with the rhythm of $2 / 4$ beats. The melody and the lyrics are closely combined to form four phrases, which are composed of $4+5+4+5$ structures. The whole song is developed around 1 (dol), 3 (me), and 6 (la). The material of the song is simple; the using a large number of lining words to enhance the expressive power of the song; using a large number of section song forms, which refers to multiple lyrics repeatedly singing the same melody.

The songs often combine a variety of forms such as dance and instrument to express a cheerful rhythm and set off a lively atmosphere. The dance steps used in the local area are relatively free. Most of them dance with the songs. The more common ones are "dancing steps". Men make fun, while women sing and act as shy little girls who chase the brother circling around the site, which is called "round step". The local antiphonal singing form with storyline and expressiveness is enthusiastically sought after by the local masses.

\section{THE ANAlysis OF THE CATtLE LANTERN SONG}

\section{A. "Song for Pasturing Cattle"}

melody is more regular, and the first melody is mainly composed of three or four degrees. The music is passionate and resounding, which falls on the A yu sound; in the second sentence, it falls on the $\mathrm{G}$ zhi sound; the third sentence converges on the A yu, corresponding to first sentence. In the fourth sentence, it converges on the $G$ zhi sound, corresponding to the second sentence. This form of melody echoing makes the structure of the song more close and complete. 


\section{放牛调}

$$
\begin{aligned}
& 1=C \frac{2}{4}
\end{aligned}
$$

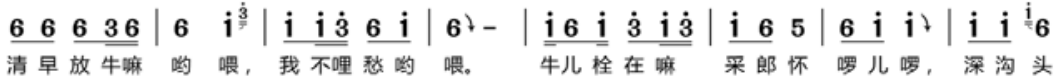

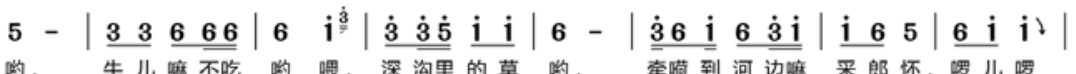

$$
\begin{aligned}
& \underset{\text { 啃 }}{6 \mathrm{i}} \frac{3^{\frac{\mathrm{i}}{5}} 6}{\text { 石 }} \mid \mathbf{5}-\|
\end{aligned}
$$

Fig. 6. Music score "song for pasturing cattle".

This cattle lantern song uses a lot of sound, glide, and lyrics in the performance of music to enhance the effect of singing. The use of a large number of decorative sounds in the song requires the singers use dexterous and brisk voice to sing the melody. The lining words such as "Cai lang huai luo er luo" and "yo, wei" are suitable for the lively characters of the "cowherds", so that it is necessary to use a more cheerful, high-pitched voice to perform a relaxed scene of pasturing cattle early in the morning. The singing of such songs pays attention to the performance of the music situation, and requires the singer to vividly depict the scenes of "cowherds" and "farming cows". Therefore, the "lantern lighter" who sings such songs must be more intimate with the cows to bring the situation of interaction between humans and cattle more vividly in the public's field of vision.

\section{B. "Cattle Lantern of Gong County"}

\section{珙县牛牛灯}

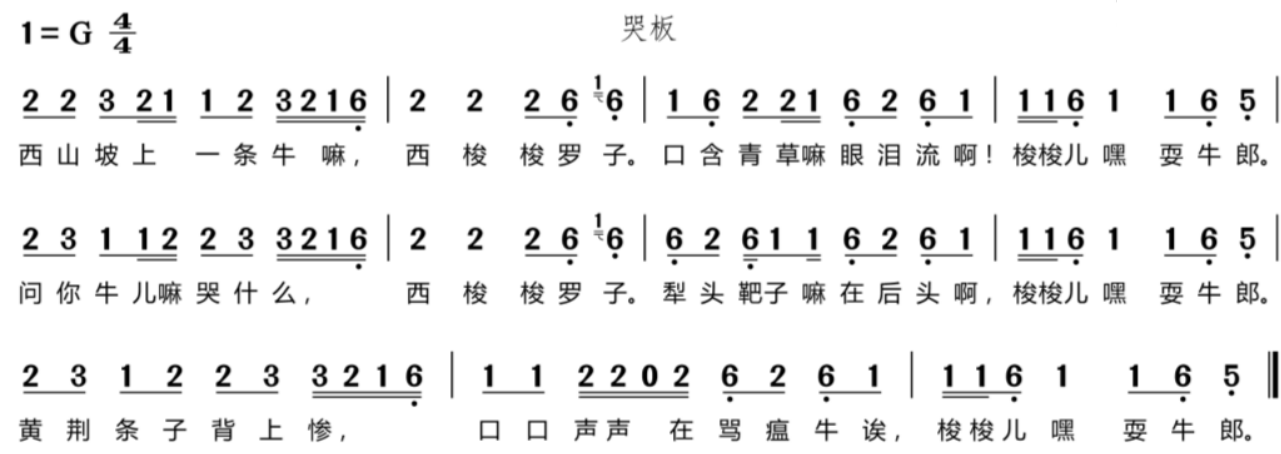

Fig. 7. Music score of "Cattle Lantern of Gong County".

Dialect notes: a cow: 一条牛 (liú), tears: 眼泪 (luì), why crying: 哭什(sí)么, plowshare: 犁头(tōu), Vitex negundo: 黄荆 (jín)条子; poor: 惨(căn), means whip, keep on saying: 口声 声(sēn), play with the cowherd:要(suá)牛郎

This "cattle lantern song" is a D zhi mode, with the 4/4 beats, and the song is a two-sentence music section consisting of lyric and lining words, as shown in "Fig. 7":
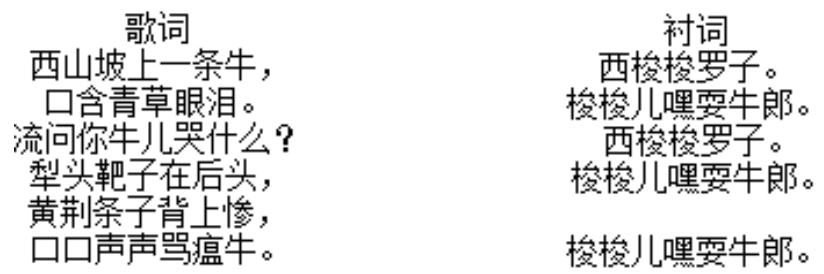

Fig. 8. Analysis of the lyrics of "cattle lantern song".
The local "cattle lantern song" are mostly composed of short lyrics and large-scale lyrics while this song evolved through material $\mathrm{xx} \mathrm{xxx}$, so the rhythm changes relatively regular. The first, third and fifth sentences of the song fall in respectively. The melody has little fluctuation, and the music is smooth.

This song "Cattle lantern of Gong County" in "Fig. 8" is a typical cattle lantern in the local area, of which the singing is full of drama. The first sentence is "a cow on the west slope, with mouth full of grass and eyes full of tears." It leads to reflection in the form of a statement: Why is the cow crying? It carries a foreshadowing of for the question "ask the cow why you cry?" At this time, the singing is mainly based on the narrative to express the sympathy of the cow, so the singing uses a softer and mellow voice. The third sentence and the fourth sentence are in the form of questions and answers: "ask the cow why you cry?" At this time, the cattle were sad and crying, and answered with a crying voice 
that "the plowshare and rake are behind me". This sentence indicates the hardship of the cows' perennial cultivation. At this time, the sad mood has reached the first climax of the song. In the fourth sentence, the emotional singer has obvious progressiveness, in order to highlight the sadness and anger of the cows when the "back is beaten by Vitex negundo". Combined with the singing content of the songs, the singing and the crying are mixed. The rhythm and speed of the song are relatively free. In the phrase "keep on curse the cattle", the tone has the feature of fling abuses. In order to show the cruelty of the farmer to the cow, the singers sang the sentence with a strong and sharp voice. In local area, this kind of natural form that combines singing performance with levels to achieve dramatic effects is called "cry board" by local people. Singers often use the sound simulating crying to express the emotions of the songs. The sound is relaxed and full of emotions, with a strong dramatic character. This form of songs based on crying is a major feature of local folk songs.

\section{The ARtistic FEATURES OF "LANTERn SONG" OF HAN PEOPLE IN GONG COUNTY}

The "lantern song" in Gong County, as an important form of local folk traditional music, has been spread in the folk through the twists and turns. These "lantern song" formed a relatively fixed melody and lyrics from mouth to mouth. In singing, a more unified singing system is formed, which forms a unique artistic feature and singing style. The following is an analysis of the artistic characteristics of local songs.

\section{A. Singing Form}

1) Evolution of the performance venues: The local "lantern song" is a form of folk music that combines singing, performance, dance, and rap. The performance venues are not fixed. As early as 1970 s to 1980 s, the local lanterns had the rule of "missing the village but not missing the household." If the host does not refuse, they must sing the lanterns songs from house to house. At this time, the host family needs to prepare a red sticker for "che yao gu", and provide tea to entertain the masses. At that time, more attention was paid to the process and form of "singing lantern songs". The performance venue was changed from the "singer" to the hosts' courtyard, and the performance proceeded in strict accordance with the order of preparing lantern, picking up lantern, singing lantern songs, and burning the lantern. Until recent years, due to the crisis of inheritance, the performance venue has changed, and they have gradually appeared in folk banquets and folk songs. The venues and sequences are no longer fixed and the content of the concerts is also based on the participation occasions, choosing songs that will make the audience emotionally resonate and match the atmosphere of the scene.

\section{2) The uniqueness of the singing forms}

a) Combination of talking and singing: The local "lantern songs" are sung when singers wander about the streets. They sing and speak all kinds of lantern songs during the performances. "The talking and singing" refers to singing while speaking. The form is mainly reflected in the custom of playing the lantern before the 1970s and 1980s. Playing lantern usually gathered a lot of onlookers. During the playing, the "lantern lighter" sang a lantern song while talking some auspicious words. The flattery words that make the onlookers feel interesting are called four words and eight sentences, such as "Thank the host for a glass of wine" and "Toasting Song". Then the locals combined these "speaking" vocals with the tune, and combined with the same number of words or the same vocal repertoire to sing as songs. It has formed the characteristics of the local lyrics: "one song with many lyrics" and "one lyrics for many songs". This combination of "speaking" and "singing" greatly enhances the lively atmosphere of the lantern ceremony and a wide variety of light words can be sung effectively.

b) Accompaniment and antiphonal singing: There are two kinds of accompaniment: one is the autonomy accompaniment--referring that in the process of singing the lantern songs, when the team singing the lantern sings to the climax part, the songs resonate with the emotions of the onlookers. At this time, the local onlookers will spontaneously accompany. The second kind is: the teams that will play the lantern rehears in advance, and sponsor others to accompany, in order to activate atmosphere and stimulate emotions when singing the songs. The role of the accompaniment is mainly to set off the mood of the song singing, render the atmosphere of the scene, and set off the vocal music of the singer, so that the singing is more appealing.

c) Singing performance and accompanying singing with dancing: The local songs are very performanceoriented, often accompanied by the setting of characters and sung with specific storylines. For example, in the song "Liu Yin Ji", the story between Liang Shanbo and Zhu Yingtai is used as the background to simulate the characters and the singing performance is lively. It is the tradition of singing local songs to play the role of the characters while adding dance steps to the singing. Among them, the dance steps are also called "movement" in the local area. The so-called "movement" is the general "walking", "twisting", "handson", "round step" and so on. For example, in "Cattle lantern", the lantern lighter will imitate the "cowherd" to amuse the cattle that is eating grass by throwing handkerchief, make a look after being chased by the cattle in a "twisting" shape, and pretend to be proud of making the cattle angry with "dancing". This is called "accompanying singing with dancing" in the local area.

\section{B. The Analysis of Music Feature}

There are many lantern songs in the local area, and there are inherent laws in the musical structure, mode and tonality, melody, rhythm and beat. Typical songs are selected for sorting and analysis as shown in "Table I" and "Table II". 
TABLE I. The Music Features of CAR LANTERn SONG

\begin{tabular}{llll}
\hline \multicolumn{1}{c}{ car lantern song } & musical structure & $\begin{array}{c}\text { mode and } \\
\text { tonality }\end{array}$ & beat \\
\hline "Liu Yin Ji" (a) & one-section mode & E jue & $4 / 4$ \\
Guess the word & one-section mode & F jue & $4 / 4$ \\
praying song & one-section mode & A yu & $2 / 4$ \\
toast eight glasses & one-section mode & G gong & $2 / 4$ \\
$\begin{array}{l}\text { of liquor to the host } \\
\text { Douyujie }\end{array}$ & one-section mode & F yu & mixed \\
& & & beats \\
\hline
\end{tabular}

TABLE II. The Music FeAtures of CAR LANTERN SONG

\begin{tabular}{|c|c|c|c|}
\hline $\begin{array}{c}\text { cattle lantern } \\
\text { songs }\end{array}$ & $\begin{array}{c}\text { musical } \\
\text { structure }\end{array}$ & mode and tonality & beat \\
\hline $\begin{array}{l}\text { cattle lantern } \\
\text { (1) }\end{array}$ & $\begin{array}{l}\text { one-section } \\
\text { mode }\end{array}$ & $\begin{array}{l}\text { change the yu mode } \\
\text { with bian gong to the } \\
\text { zhi mode with bian } \\
\text { gong }\end{array}$ & $\begin{array}{l}\text { mixed } \\
\text { beats }\end{array}$ \\
\hline $\begin{array}{l}\text { cattle lantern } \\
(2)\end{array}$ & $\begin{array}{l}\text { one-section } \\
\text { mode }\end{array}$ & $\begin{array}{l}\text { zhi mode in bB gong } \\
\text { system }\end{array}$ & $2 / 4$ \\
\hline $\begin{array}{l}\text { song for } \\
\text { pasturing cattle }\end{array}$ & $\begin{array}{l}\text { one-section } \\
\text { mode }\end{array}$ & G zhi & $\begin{array}{l}\text { mixed } \\
\text { beats }\end{array}$ \\
\hline $\begin{array}{l}\text { Cattle lantern } \\
\text { of Gong county }\end{array}$ & $\begin{array}{l}\text { one-section } \\
\text { mode }\end{array}$ & D zhi & $4 / 4$ \\
\hline
\end{tabular}

1) Mode, tonality and musical form: The modes of local lantern song are mainly pentatonic mode, while the car lantern songs mainly use jue and yu mode, as shown above: "Liu Yin Ji" and "Guessing Words" is jue mode; "Dou Yu Jie" and "Toast Song" are yu mode. Relatively speaking, the mode of local cattle lantern song is a little single, mostly based on the zhi mode. Most of the lantern songs passed down from word to mouth is not recorded in the music score. The singing is mostly impromptu, so the speed, intensity, volume, and pitch of each song are different according to the singers' emotion changes in the singing process. The local lantern songs are all in a single one-section mode, showing the characteristics of the Chinese folk song "correspondence between beginning and end". For example, "6 31 " at the end of the first phrase and "1 61 " at the beginning of the second phrase in "Guessing Words" reflect the feature "correspondence between beginning and end", as shown in the "Fig. 9".

\section{猜字}

$$
\begin{aligned}
& 1={ }^{\#} \mathrm{C} \frac{\mathbf{4}}{\mathbf{4}}
\end{aligned}
$$

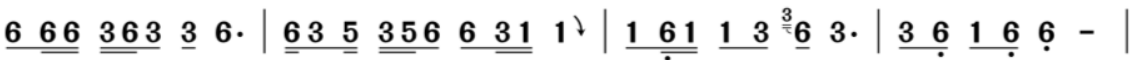

$$
\begin{aligned}
& \text { 1. (男) 一墂嘛 在头上, } \\
& \text { 十字在 中央咆 } \\
& \text { 喂。八字两边放噻, 日子脚下藏。 } \\
& \text { 2. (男) 一 点嘛 - 横 长, } \\
& \text { 3. (男) 一点嘛 - 横长, } \\
& \text { 一飘到 南洋哅 } \\
& \text { 喂。两颗林阴木噻, 生在石头上。 } \\
& \text { 喂。上十对下十噻，太阳对月亮。 }
\end{aligned}
$$

Fig. 9. The music score of "Guess the Word".

In the picture of "Cattle Song of Gong County", "2 616 " of the first phrase and the "1 62 2 1 " between the second phrase also show the musical characteristics of "correspondence between beginning and end", as shown in "Fig. 10".

\section{珙县牛牛灯 \\ $1=G \frac{4}{4}$ \\ 哭板 \\ 珙县民歌 词 \\ 江丽记谱 曲

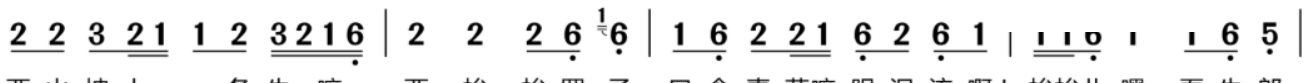 \\ 西山坡上一条牛嘛, 西梭梭罗子。口含青草嘛眼泪流啊! 梭梭儿嘿 要牛郎。}

Fig. 10. The music score of "Cattle Song of Gong County".

2) Characteristics of melody, beat and rhythm: After sorting out the collected music scores, it can be seen that the range of local lantern songs is narrow, the span is mostly within six or seven degrees, the melody develops with threedegree and four-degree intervals and the rhythm of the song is regular and compact. The most common rhythm are the first eight and last sixteen, and the first eight and last points rhythm, while the most common beats are $2 / 4,4 / 4$. There are also mixed beats with regular rhythm and rhyme of the songs that are conducive to singing. On the other hand, the songs mostly ends in the same melody of "1 65 ", which also forms the intrinsic style of songs in Gong county in terms of music materials.

3) Characteristics of lining words: The local lyrics match the fixed melody with the corresponding lyrics. When there is an asymmetry between the lyrics and the melody, they will use the lining words such as ah, ya, yo, ei, wei, ne, sha, ai, an, ma, chi and so on to adjust the rhythm and 
alignment of the lyrics. For example, although there are a total of nine paragraphs in"Liu Yin Ji" (1), the melody is relatively fixed, and the number of lyrics is seven words. When the number of lyrics and melody in the song is asymmetric, the lining words "yowei" and "aiyowei" are used to adjust the correspondence between the lyrics and the melody. At the same time, as a modal modifier, it modifies the melody of the song and adjusts the singer's singing mood. There are also special lining words in the local area. For example, in "cattle lantern", the lining words "yi er yi", "nanjing is big", "ma li lai duo", "snowflakes fly", "ya huo er hei", "xi suosuo luozi", etc are typical onomatopoeia, in order to imitate the sounds of farmers and cattle farming. Such words are mostly created by the local people extemporaneously, mainly to express the high spirit in labor.

Through the sorting of the "lantern song" in Gong county of Yibin, Sichuan Province, it can be seen that there are many kinds of local lyrics with long content, involving historical stories, folklore, modern love, seasonality, life, etc. After exploration and analysis of the singing form, vocal form, performance form, accompaniment instrument, and artistic features of the lyrics with rich content, it can be found that the lantern song of Han people in Gong County is influenced by the local geographical environment and humanities, and has formed the inherent regional features of the local area. The lyrics of songs form the characteristics of "one song with many lyrics" and "one lyric for many songs". In lineage and development of the years, the art form of songs formed the local singing system. It is of great significance to inheriting the national folk music culture, carrying forward the national spirit, broadening the horizon and improving individuals' art aesthetic ability to analyze and sort it.

\section{CONCLUSION}

Yibin County has always been a place where minorities live together. The powerful "Bo people" once lived there, leaving many precious cultural heritages that still influence the present. Multiple ethnic groups living here for a long time forms the characteristics of diversified development of local music culture. In the long history, the people of all ethnic groups in Gong County adhere to their own unique traditional culture, forming the unique characteristics of the local "lantern song", but with the development of society, these traditional cultures and customs are slowly overwhelmed. Many old people who can sing local "lantern song" have slowly passed away. Therefore, this research has certain practical significance: as a native Yibin people, the author hopes to contribute to the continuation and development of intangible cultural heritage of the hometown, let the extinguished "lantern song" in the folk and interesting custom of "singing lantern" be presented to future generations in the form of text and music data, so that more people can feel the local music culture intuitively, which has a certain effect on inheriting and protecting the local "lantern song"; the research on it is also in line with the call of "inheriting and popularizing the folk culture to enhance the influence of local cultural, which plays an important role in excavating the historical life of local people and promoting lantern song of Han people in Gong County.

\section{REFERENCES}

[1] Chen Wan. How to sing the folk songs of Sichuan and Chongqing [M]. Sichuan: Sichuan Literature and Art Publishing House, 2008.3237.

[2] Jiang Mingdun. Introduction to Chinese National Music [M]. Shanghai: Shanghai Music Publishing House, 2016.40-82.

[3] Jiang Mingdun. An overview of Han folk songs. [M] Shanghai: Shanghai Literature and Art Publishing House, 1981.202-339.

[4] Yang Mingkang. Chinese folk songs and local society [M], Jilin: Jilin Education Press, 1993.205-230.

[5] Tan Weiwei. "Study on the Artistic Characteristics of Yibin Qilian Mountain Song" [D], Sichuan Conservatory of Music, 2016.

[6] Lei Xiaolan. "The Characteristics and Inheritance of Ancient Songs in Southern Sichuan" [J], Contemporary Music, 2015, 5.

[7] Mao Keqiang. "The Flos Sophorae Blossoms in the Spring Breeze-Comment on the Modern Sichuan Opera "When will the Flos Sophorae Blossom"[J], Sichuan Drama, 2011, 5.

[8] Liu Yutong. "A Review of the research of Music in Yibin, Sichuan" [J], Music Creation, 2011, 7.

[9] Huang Xiaohui, "Overview of Yibin Folk Songs in Southern Sichuan" [J], Great Wall, 2009,10.

[10] The Propaganda Department of the Communist Party of China in Gong county, "Davidia Involucrata" [J], Bureau of Culture, Radio, Film and Television Publishing of Gong county, 2014, 1.

[11] The Propaganda Department of the Communist Party of China in Gong county, "Davidia Involucrata" [J], Bureau of Culture, Radio, Film and Television Publishing of Gong county, 2014, 2. 